\title{
FORMAÇÃO DE BIOFILME EM DIFERENTES MATERIAIS SUPORTE NO TRATAMENTO BIOLÓGICO DE ESGOTO SANITÁRIO
}

\author{
Ana Carolina Pierotti Jacobs ${ }^{1}$ \\ Camila Zoe Correa $^{2}$ \\ Kátia Valéria Marques Cardoso Prates $^{3}$
}

\begin{abstract}
RESUMO
Dentre as técnicas empregadas no tratamento de esgoto sanitário, o tratamento biológico com biomassa aderida (biofilme) vem sendo utilizado com sucesso. Entretanto, a escolha do material suporte pode influenciar de forma positiva na eficiência do processo. Devido o exposto o principal objetivo deste trabalho foi avaliar a influência do tipo de material suporte na formação de biofilme em um reator em bateladas sequenciais aerado (RBSa) alimentado com esgoto sanitário. Como material suporte foram utilizados espuma de poliuretano e bucha vegetal (Luffa cylindra). Para acompanhar o desenvolvimento do biofilme nestes materiais realizou-se a quantificação de bactérias heterotróficas aderidas $(\mathrm{BH})$ por meio da contagem padrão em placa. Foram determinadas também a biomassa seca aderida (g) e a concentração de polissacarídeos aderidos (mg/L), sendo os resultados analisados estatisticamente (ANOVA: um critério, com nível de confiança: 0,01). Os resultados indicaram que na bucha vegetal havia mais material aderido do que na espuma de poliuretano, demostrando que este tipo de material suporte proporciona maior adesão de microrganismos.
\end{abstract}

PALAVRAS-CHAVE: Reator em bateladas sequencias aerado. Espuma de poliuretano. Bucha vegetal.

\section{BIOFILM TRAINING IN DIFFERENT MATERIALS SUPPORT IN BIOLOGICAL WASTEWATER TREATMENT HEALTH}

\begin{abstract}
Among the techniques used in the treatment of sewage, biological treatment with attached biomass (biofilm) has been successfully used. However, the choice of the support material can positively influence the process efficiency. Due to the above the main objective of this study was to evaluate the influence of type of support material in the biofilm formation in a reactor in aerated sequencing batch (RBSA) fed with sewage. As support material were used polyurethane foam and loofa sponge (Luffa cylindra). To follow the development of the biofilm in these materials was held quantifying attached heterotrophic bacteria $(B H)$ by standard plate count. Also it was determined adhered dry biomass $(g)$ and the concentration of bonded polysaccharides $(\mathrm{mg} / \mathrm{L})$, and the results were statistically analyzed (ANOVA: a criterion, with a confidence level: 0.01). The results indicated that the loofa sponge had adhered more material than in polyurethane foam, showing that this type of support material provides greater adhesion of microorganisms.
\end{abstract}

\footnotetext{
${ }^{1}$ Engenheira Ambiental. Universidade Tecnológica Federal do Paraná. carolinapierotti@gmail.com.

${ }^{2}$ Mestranda em Engenharia Ambiental. Programa de Pós-graduação da Universidade Tecnológica Federal do Paraná. camila.z.correa@gmail.com.

${ }^{3}$ Doutora em Ciências da Engenharia Ambiental, Programa de Pós-graduação da Universidade Tecnológica Federal do Paraná. kvprates@utfpr. edu.br.
} 
KEYWORDS: Reactor in batch sequences aerated. Polyurethane foam. loofa sponge.

\section{FORMACIÓN BIOFILM EN DIFERENTES MATERIALES DE APOYO EN SALUD TRATAMIENTO BIOLÓGICO DE AGUAS RESIDUALES}

\section{RESUMEN}

Entre las técnicas utilizadas en el tratamiento de aguas residuales, tratamiento biológico con biomasa adjunto (biofilm) ha sido utilizado con éxito. Sin embargo, la elección del material de soporte puede influir positivamente en la eficiencia del proceso. Debido a lo anterior, el objetivo principal de este estudio fue evaluar la influencia del tipo de material de apoyo en la formación de biopelículas en un reactor discontinuo secuencial en aireada (CSPO) alimentado con aguas residuales. Como material de apoyo se utilizaron espuma de poliuretano y estropajo (Luffa CYLINDRA). Para seguir el desarrollo de la biopelícula en estos materiales se celebró de cuantificación adjunta bacterias heterótrofas $(\mathrm{BH})$ de recuento en placa estándar. También se determinó adhirió biomasa seca $(\mathrm{g})$ y la concentración de polisacáridos unidos ( $\mathrm{mg} / \mathrm{L}$ ), y los resultados fueron analizados estadísticamente (ANOVA: un criterio, con un nivel de confianza: 0,01). Los resultados indicaron que la esponja se había adherido más material que en espuma de poliuretano, que muestra que este tipo de material de soporte proporciona una mayor adhesión de los microorganismos.

PALABRAS CLAVE: Reactor en secuencias por lotes aireada. La espuma de poliuretano. loofah.

\section{INTRODUÇÃO}

A poluição de corpos hídricos superficiais pelo lançamento sem tratamento prévio de esgoto sanitário ainda é um dos problemas ambientais em países em desenvolvimento, trazendo efeitos negativos para saúde ambiental e humana, prejudicando a manutenção das condições básicas de qualidade d'água para seus diversos usos.

Dentre os processos utilizados para o tratamento de esgoto sanitário, o tratamento biológico é uma das alternativas empregadas com sucesso já há algumas décadas, sendo este baseado no papel natural dos microrganismos na ciclagem de elementos como Carbono (C) e Nitrogênio (N) (COMEAU, 2008). O processo de tratamento biológico pode ser utilizado em diversas plantas, sendo estas operadas com biomassa em suspensão ou aderida (biofilme) (MELO, 1996).

O uso de biomassa aderida em um sistema de tratamento confere vantagens, como unidades mais compactas, devido a utilização da alta área superficial do biofilme, além de taxas volumétricas de carregamento maiores e baixo requerimento de energia (O'REILLY et al., 2008). Outra vantagem é o favorecimento do processo de remoção biológica de nitrogênio dentro do sistema, pois com a 
formação do biofilme na superfície de um material suporte, camadas aeróbias seguidas de anaeróbias podem ser formadas, o que favorece o desenvolvimento dos organismos autotróficos aeróbios em camadas superiores e os anaeróbios nas inferiores.

A formação de biofilme por organismos autotróficos e heterotróficos pode ocorrer em diferentes materiais como plásticos, metais, vidro, partículas sólidas, madeira entre outros materiais (KOKARE et al., 2009), porém em alguns superfícies este desenvolvimento pode ser favorecido ou não, dependo das características físicas, como rugosidade, porosidade e tamanho dos poros (HUYSMAN et al., 1983; WOLFF et al., 2010), sendo que a extensão da colonização microbiana em uma superfície, pode aumentar proporcionalmente com a rugosidade superficial do material (CHARACKLIS et al., 1990).

A espuma de poliuretano é um material suporte largamente utilizado em sistemas de tratamento biológico com biomassa aderida, fornecendo condições ambientais adequadas para o crescimento e retenção da biomassa microbiana. Devido às características deste material o mesmo já foi e é ainda muito utilizado (GARCIA et al., 2007; WOSIACK et al.; 2015).

Outro material que pode ser utilizado como material suporte é a bucha vegetal (Luffa cylindra). Esta é conhecida como uma ferramenta biotecnológica com diversas aplicações, e utilizada com êxito desde 1993 como matriz para imobilização de células biológicas (SAEED e IQBAL, 2013).

Este tipo de material suporte é indicado pelas suas características como: elevada porosidade, propriedades física estáveis, biodegradabilidade, não-toxicidade e baixo custo (YU-KUO LIU et al., 1998). Estes conjunto de características indicam a bucha vegetal como uma boa alternativa aos materiais suportes utilizados.

Devido à influência do tipo de material suporte no desenvolvimento e formação do biofilme, o presente trabalho teve como principal objetivo avaliar a formação de biofilme em espuma de poliuretano e bucha vegetal (Luffa cylindra) empregados no processo de tratamento biológico de esgoto sanitário, em um reator em bateladas sequenciais aerado (RBSa). 


\section{Periádica Eletranica $\quad$ ISSN 1980-0827 \\ Fórum Ambiental \\ da Alta Paulista \\ Volume 11, Número 08, 2015 \\ Saúde e Saneamento Ambiental}

\section{METODOLOGIA}

\subsection{Sistema operacional experimental}

Para o desenvolvimento da pesquisa foram confeccionados dois reatores independentes em policloreto de vinil (PVC), em escala piloto, com $16 \mathrm{~cm}$ de comprimento, $12 \mathrm{~cm}$ de largura e $17 \mathrm{~cm}$ altura, com volume útil de 3 litros, sendo $50 \%$ do volume preenchido com material suporte. Estes reatores foram operados em bateladas sequencias, por 42 dias, com Tempo de Detenção Hidráulico (TDH) de 48 horas e aeração constante, alimentados com esgoto sanitário bruto proveniente de uma Estação de Tratamento de Esgoto (ETE) situado na cidade de Londrina-Pr.

Cada reator foi preenchido com um tipo de material suporte: o Reator em Bateladas Sequencias 1 (RBSE) preenchido com cubos de $1 \mathrm{~cm}^{3}$ de espuma de poliuretano e o Reator em Bateladas Sequencias 2 (RBSB) preenchido com bucha vegetal.

No interior do reator ainda foi acondicionado um suporte com lâminas de vidro, para possibilitar o monitoramento semanal em microscópio óptico dos microrganismos presentes no interior do reator.

\subsection{Parâmetros microbiológicos}

As análises microbiológicas visaram caracterizar quantitativamente a colonização dos materiais suportes, de forma a observar a evolução da adesão dos microrganismos. Os testes realizados e a frequência de análise podem ser visualizados na Tabela 1.

Tabela 1. Parâmetros microbiológicos e frequência de análise.

\begin{tabular}{|c|c|c|}
\hline & PARÂMETRO & FREQUÊNCIA \\
\hline \multirow{4}{*}{ Quantitativo } & Bactérias Heterotróficas & Semanal \\
\hline & Massa seca da biomassa & Semanal \\
\hline & Polissacarídeos totais & Semanal \\
\hline & $\begin{array}{c}\text { Bactérias Nitrificantes e } \\
\text { desnitrificantes }\end{array}$ & Início e final do processo \\
\hline Qualitativo & $\begin{array}{c}\text { Á fresco das lâminas } \\
\text { acondicionadas no fundo dos } \\
\text { reatores }\end{array}$ & Semanal \\
\hline
\end{tabular}

Fonte: Autoria própria, 2015. 
Para realizar a separação das bactérias heterotróficas, nitrificantes e desnitrificantes aderidas ao material suporte, para sua posterior quantificação, foram seguidos os seguintes passos: cada material suporte retirado do reator foi inserido separadamente em um tubo Falcon $(50 \mathrm{~mL})$ estéril contendo $10 \mathrm{~g}$ de pérolas de vidro e $10 \mathrm{~mL}$ de solução de Triton X-100 a 0,1\%. O tubo Falcon então era agitado em equipamento Vortéx por 10 minutos para desprendimento das bactérias do meio suporte, obtendo-se assim a diluição $10^{-1}$.

Após este procedimento seguiu-se com a diluição em série da amostra, em solução salina 0,85\%. Para determinação do número de organismos heterotróficos presente no material suporte foi utilizado o método da contagem padrão em placa, sendo o resultado expresso em Unidades Formadoras de Colônia por mL (UFC/mL). Para o cultivo dos organismos heterotróficos foi utilizado o meio de cultura Plate Count Ágar (PCA).

A quantidade de biomassa aderida aos suportes ao longo do estudo foi avaliada verificando a variação da massa seca de biomassa aderida, utilizando a metodologia proposta por Schneider (2010). Esse procedimento é fundamentado na diferença da massa antes e depois da inserção do material. Para cada determinação foram retirados de cada reator 2 materiais suportes.

Os polissacarídeos da biomassa aderida foram determinados após a lise completa das células aderidas e estimado pelo método colorimétrico de Dubois (1956), com o preparo da amostra seguindo o procedimento descrito por Schneider (2010).

A estimativa do número mais provável por $100 \mathrm{~mL}(\mathrm{NMP} / 100 \mathrm{~mL})$ de bactérias nitrificantes e desnitrificantes foi realizada segundo metodologia utilizada por Mendonça (2002).

O cálculo do NMP/100mL foi feito a partir da combinação das respostas positivas, utilizando a Tabela Padrão de Probabilidade encontrada em APHA (2005).

\subsection{Parâmetros físico-químicos}

Foram monitorados os seguintes parâmetros físico-químicos no efluente: pH e temperatura -diariamente, nitrogênio amoniacal, nitrito e nitrato ao final do processo de tratamento (APHA, 2005). No final do período operacional realizou-se 
um ensaio para determinação da Taxa de Consumo de Oxigênio (TCO) nos reatores.

\subsection{Analise estatística dos dados}

A análise estatística dos dados quantitativos foi realizada no software livre Bioestat 5.0, utilizando o teste de hipótese ANOVA (um critério), com um nível de decisão: alfa $=0,01$ ( $p$-valor $<0,01$ ), para verificar se houve diferença significativa entre os resultados de bactérias heterotróficas, biomassa aderida e polissacarídeos nos matérias suporte utilizados.

\section{RESULTADOS E DISCUSSÃO}

3.1 Bactérias Heterotróficas, biomassa seca aderida e concentração de polissacarídeos

Os resultados para UFC/mL de bactérias heterotróficas e biomassa seca aderida na espuma de poliuretano e bucha vegetal são presentados na Figura 1.

Figura 1. a) UFC/mL de bactérias heterotróficas aderidas b) biomassa seca aderida a bucha vegetal e espuma de poliuretano.

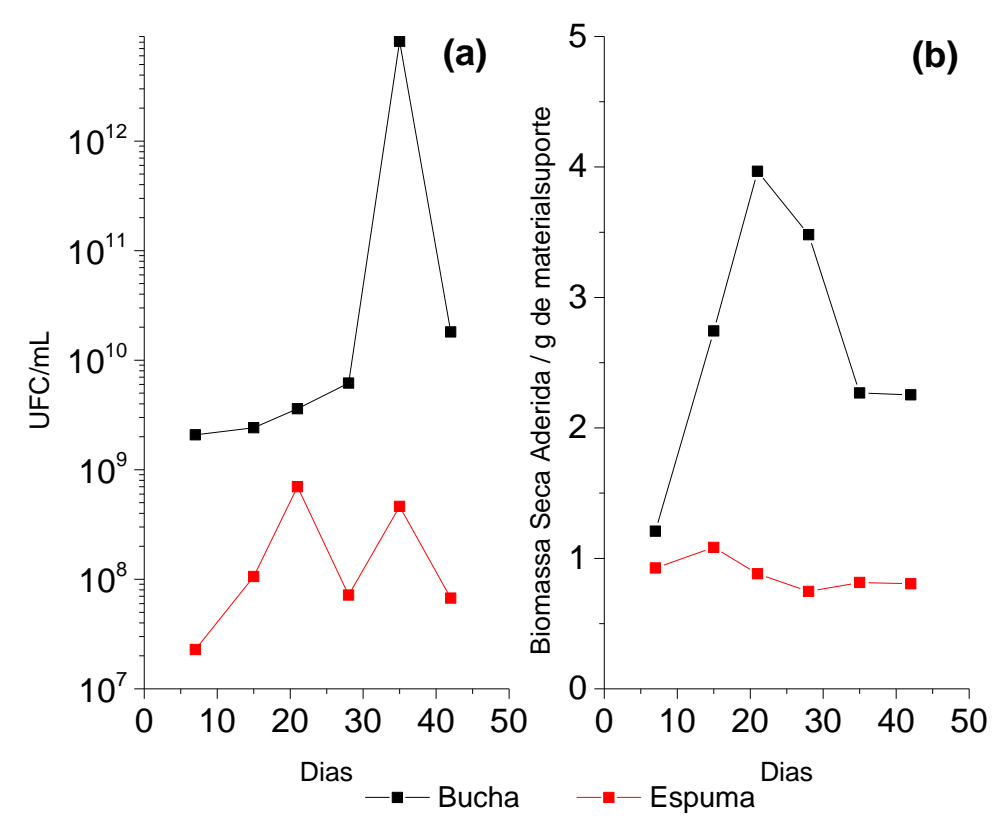

Fonte: Autoria própria, 2015. 
No primeiro dia de operação dos reatores foi obtida a concentração inicial de $\mathrm{BH}$ presentes no efluente, sendo esta de $1,08.10^{8} \mathrm{UFC} / \mathrm{mL}$ e após 7 dias de operação foi obtido a primeira concentração de $\mathrm{BH}$ presentes na espuma e na bucha vegetal.

$\mathrm{Na}$ Figura 1a observa-se que na bucha vegetal houve tendência de aumento no número de bactérias heterotróficas até $035^{\circ}$ dia de operação, variando de $2,08.10^{9} \mathrm{UFC} / \mathrm{mL}$ à $8,13.10^{12} \mathrm{UFC} / \mathrm{mL}$ no $35^{\circ}$ dia. Porém do $35^{\circ}$ para $42^{0}$ dia foi constatada uma redução no valor de UFC/mL neste material suporte, chegando as bactérias heterotróficas a contabilizarem $1,81.10^{10} \mathrm{UFC} / \mathrm{mL}$. Esta redução no número de organismos aderidos pode estar ligada a um processo de desprendimento do biofilme, sendo este um processo natural, causado pela erosão ou abrasão no mesmo (MELO, 2003).

No RSBE o número de UFC/mL não apresentou grande variação ao longo dos dias de operação, tendo um comportamento constante, com valores de UFC/mL variando de $2,28 \cdot 10^{7}$ a $4,63 \cdot 10^{8}$. Estes resultados demostram que o biofilme deve ter ficado mais fino, em função das condições ambientais presentes no reator.

Os resultados para biomassa seca aderida (Figura 1b) apontam que ao longo do período de operação do reator a bucha vegetal apresentou uma tendência de aumento, com média de 2,65 $\pm 0,98 \mathrm{~g}$ de sólidos aderidos/ g material suporte. $\mathrm{Na}$ espuma de poliuretano, como foi constato nos resultados de $\mathrm{UFC} / \mathrm{mL}$, a concentração de biomassa seca também foi praticamente constante, apresentando valor médio de $0,88 \pm 0,12 \mathrm{~g}$ de sólidos aderidos/ g material suporte, com valores abaixo dos obtidos para bucha vegetal.

O comportamento da biomassa seca aderida pode estar relacionado com a espessura do biofilme. Os resultados indicam que na bucha vegetal o biofilme era espesso, apresentando elevado crescimento microbiano.

Segundo Schneider (2010), a atividade do biofilme não é proporcional à quantidade de biomassa fixa, entretanto aumenta com a espessura do biofilme até um determinado nível. Após esse nível o consumo de substrato ao longo do biofilme pode privar estes nas camadas mais internas, diminuindo assim sua atividade.

O aumento na quantidade de sólidos aderidos a bucha vegetal até o $21^{0}$ dia de operação, indica que a formação do biofilme foi favorecida logo no início do período operacional do reator, porém após este período observou-se redução na 
quantidade de biomassa seca aderida. Acredita-se que esta diminuição esteja associada à biodegradação da bucha, visivelmente perceptível após o $21^{0}$ dia.

Agra (2009) trabalhando com a bucha vegetal como material suporte constatou este mesmo problema, indicando que por ser um material biodegradável, este apresenta um período útil relativamente curto tendo que ser trocada periodicamente.

A concentração de polissacarídeos na bucha vegetal chegou a um valor médio de 1,52 $\pm 0,34 \mathrm{mg} / \mathrm{L}$ e na espuma de 0,34 $\pm 0,31 \mathrm{mg} / \mathrm{L}$. Estes resultados indicam que a espessura do biofilme na bucha foi maior do que na espuma.

A estrutura dos biofilmes é composta de micro-colônias de células envoltas por uma matriz de substâncias poliméricas (EPS), onde os canais hidrodinâmicos que separam as micro-colônias proporcionam a difusão de nutrientes, oxigênio e detritos (COHN; HAYES e RENAULT, 2010). Os EPS são os principais componentes da matriz do biofilme, definido como uma mistura complexa de biopolímeros, tendo como principal componente os polissacarídeos (KOKARE et al., 2009 e COHN; HAYES e RENAULT, 2010).

Da análise estatística realizada (ANOVA: um critério), obteve-se que não houve diferença significativa (nível de confiança: 0,01 ) entre os valores de UFC/mL obtidos em ambos os materiais, mesmo tendo-se resultados de UFC/mL maiores na bucha vegetal. Já analisando os dados de concentração de polissacarídeos e biomassa seca aderida, a análise estatística apontou que houve diferença significa, demonstrando que na bucha vegetal havia mais material presente do que na espuma de poliuretano.

A análise estatística para polissacarídeos e biomassa seca aderida indica que a bucha vegetal neste sistema de tratamento possui mais organismos aderidos do que a espuma de poliuretano. Este resultado pode ser devido às características deste material suporte, visto que este é constituído por retículos aleatórios, com pequenas seções transversais acopladas, com porosidade elevada (79-93\%), com densidade baixa $\left(0,02-0,04 \mathrm{~g} / \mathrm{cm}^{3}\right)$ e volume específico de poro elevado (21-29 $\mathrm{cm}^{3} / \mathrm{g}$ ) sendo estas características de um bom suporte para imobilização de biomassa (SAEED e IQDAL, 2013). 
Elevada porosidade e área superficial juntamente com a uniformidade na distribuição de poros de um material suporte, pode resultar em rápida colonização deste e estabilidade no processo (BREITENBUCCHER et al., 1990).

A bucha vegetal é um material suporte já utilizado em diversos experimentos. Pekdemir et al. (2003) mostraram que a bucha vegetal é muito eficiente como material suporte para imobilização da Thiobacillus ferrooxidans no tratamento de águas residuárias industriais com elevados teores de ferro.

Yu-kuo liu et al. (1998) utilizando espuma de poliuretano e bucha vegetal como material suporte para imobilização de biomassa, constatou que a capacidade de imobilização da bucha encontrada foi comparável a da espuma de poliuretano utilizada, independentemente do tempo de cultivo, constando que a bucha pode ser utilizada como um excelente suporte para imobilização de células.

A maior eficiência de adesão de microrganismos a bucha pode ser atribuída a sua estrutura, pois segundo Ogbonna et al. (2001) quanto maior a área disponível por unidade de volume, maior será a comunidade microbiana e eficiência do sistema.

\subsection{Organismos nitrificantes e desnitrificantes}

Na Figura 2 são apresentados os resultados do NMP/100mL dos organismos nitrificantes e desnitrificantes presentes no efluente (no início da operação dos reatores) e nos materiais suportes (no final do período de operação dos reatores).

Figura 2. NMP/mL de bactérias nitrificantes e desnitrificantes presente no efluente no início do experimento e nos matérias suportes no final da operação dos reatores.

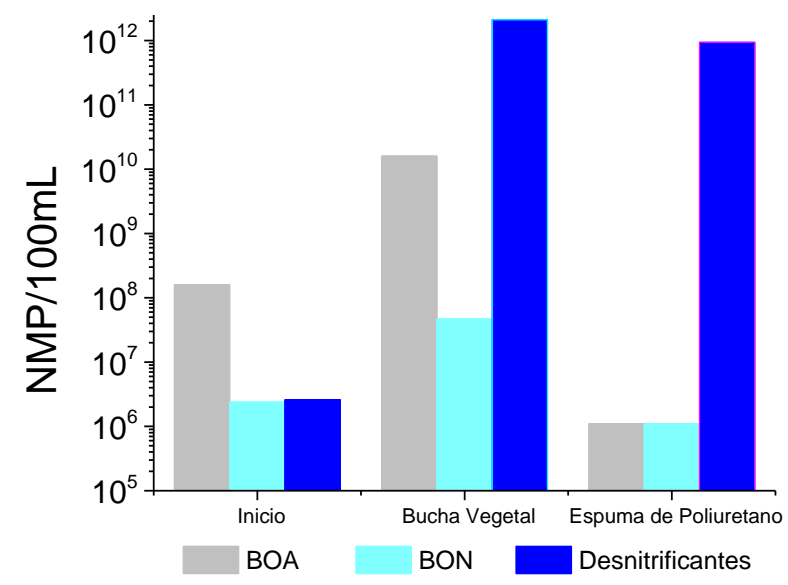

Fonte: Autoria própria, 2015 
No efluente, o valor do NMP/100mL de BOA foi de $1,6.10^{8} \mathrm{NMP} / 100 \mathrm{~mL}$ e na bucha vegetal e na espuma de poliuretano foram de $1,6.10^{10} \mathrm{NMP} / 100 \mathrm{~mL}$ e $1,1.10^{6}$ $\mathrm{NMP} / 100 \mathrm{~mL}$, respectivamente. Para as BON obteve-se $2,4.10^{6} \mathrm{NMP} / 100 \mathrm{~mL}$ no efluente e 4,7.10 $\mathrm{NMP} / 100 \mathrm{~mL}$ e $1,1.10^{6} \mathrm{NMP} / 100 \mathrm{~mL}$ na bucha e na espuma, respectivamente.

Observa-se dos resultados (Figura 2) que o NMP/100mL de BOA foi superior ao das BON, nos dois materiais suportes analisados. Este resultado pode estar ligado ao metabolismo destes organismos e as condições operacionais do reator, pois em temperaturas acima de $15^{\circ} \mathrm{C}$ as $\mathrm{BOA}$ crescem mais rápido do que as $\mathrm{BON}$ (PAREDES et al., 2007). Em ambos os reatores a temperatura média obtida foi de $23,5 \pm 3^{\circ} \mathrm{C}$, com temperatura mínima de $16,7^{\circ} \mathrm{C}$ e máxima de $27,8^{\circ} \mathrm{C}$.

Os valores de $\mathrm{pH}$ medido no efluente nos dois reatores também foi o

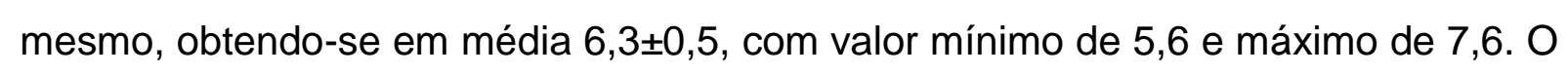
$\mathrm{pH}$ do esgoto sanitário afluente foi em média 6,4 40,3 , com valor mínimo de 5,9 e máximo de 7,1 .

O efluente permaneceu na maior tempo com $\mathrm{pH}$ abaixo de 7 , isto pode ter afetado de forma significativa a ação dos organismos nitrificantes presentes no reator, pois em $\mathrm{pH}$ na faixa ácida a formação de ácido nitroso é favorecida. Segundo Villaverde (2004) em pH inferior a 6,5 o processo de nitrificação praticamente para, por falta de amônia livre no meio e altas concentrações de ácido nitroso.

A concentração de $\mathrm{N}$-amoniacal no afluente no final do processo foi de 77,39 $\mathrm{mg} \mathrm{N}-\mathrm{NH}_{3} / \mathrm{L}$. Na saída do RBSB a concentração deste foi de 35,06 mg N-NH$/ 2$ e no RBSE de $36,63 \mathrm{mg} \mathrm{N}-\mathrm{NH}_{3} / \mathrm{L}$. Este resultado confirma a ação das BOA no meio, demostrando que mesmo a concentração destas no RBSB sendo maior a ação deste grupo de bactérias no processo de conversão de $\mathrm{N}$-amoniacal a nitrito não foi mais eficiente neste reator. Observa-se que apenas cerca de $50 \%$ do $\mathrm{N}$-amoniacal no efluente foi utilizado. Esta baixa eficiência na atividade destes organismos pode ter ocorrido devido às características físico-químicas do meio.

A concentração de nitrito no efluente no RBSB foi de $18,63 \mathrm{mg} / \mathrm{L}$ e nitrato de 42,38 mg/L, já no RBSE a concentração de nitrito foi de 17,25 mg/L e de nitrato de 10,39 mg/L. Destes resultados observa-se que não houve acúmulo de nitrito em ambos os sistemas. 
Nota-se da Figura 2 que o número de bactérias desnitrificantes foi superior ao das nitrificantes em todos os materiais suportes. Este fato também esta atrelado ao metabolismo destes organismos, visto que estes são em sua maioria heterotróficos e possuem um rendimento energético cerca de cinco vezes maior que o das bactérias nitrificantes autotróficas (BITTON, 2005).

No efluente a concentração de bactérias desnitrificantes foi de 2,6.10 NMP/100 mL no início da operação dos reatores e na bucha vegetal e na espuma foi de $2,1.10^{12} \mathrm{NMP} / 100 \mathrm{~mL}$ e $9,4.10^{11} \mathrm{NMP} / 100 \mathrm{~mL}$, respectivamente.

No geral dos resultados observa-se que a bucha vegetal possui um número maior de organismos aderidos do que a espuma de poliuretano, o que demostra que este material é mais favorável à aderência de organismos do que espuma.

Agra (2009) constatou em seu trabalho que a bucha vegetal (Luffa cylindrica) foi um excelente material suporte para o desenvolvimento do biofilme, agregando microrganismos capazes de metabolizarem os compostos orgânicos e inorgânicos adsorvida sobre ele, particularmente aqueles responsáveis pela nitrificação.

Em sistemas que visam à remoção biológica de nitrogênio, a utilização de materiais que favorecem a aderência dos organismos presentes no sistema, é algo favorável, visto que os organismos nitrificantes possuem baixo rendimento celular e crescimento lento, assim a fixação destes a materiais suportes acaba se tornando um elemento atrativo (EGLI et al., 2003).

\subsection{Análise em microscópio dos microrganismos presentes no lodo}

As análises microscópicas auxiliam na identificação da tendência de funcionamento do reator, podendo demonstrar a eficiência da remoção de matéria orgânica, a adequação da aeração empregada e revelar a ocorrência de sobrecargas orgânicas (VAZOLLER, 1989).

A observação à fresco em microscópio óptico das lâminas acondicionadas no fundo dos reatores revelou a presença de protozoários do grupo dos ciliados (Ciliados Fixos), amebas (Tecamebas), flagelados e micrometazoários (rotíferos).

Nas lâminas presentes no fundo do RBSE foi observado a presença de protozoários ciliados pedunculados semelhantes à Vorticella covalaria e protozoários livres, além de muitos rotíferos. Segundo Figueiredo e Domingues (1997) a 
predominância de ciliados fixos e livres indica boas condições de depuração no sistema.

Neste reator também foi observado na ultima semana de análise, a presença de Tecamebas, o que caracteriza períodos de bom desempenho de nitrificação (EIKELBOOM, 2000).

Nas lâminas retiradas do fundo do RBSB foi observado estes mesmo organismos, porém com uma frequência menor. Muito protozoários ciliados são predadores de bactérias (FIGUEIREDO e DOMINGUES, 1997), podem consumir estes organismos presentes no biofilme. $O$ fato destes organismos serem observados em menores quantidades no reator com bucha vegetal pode ter favorecido a formação do biofilme neste material suporte.

\subsection{Respirometria}

A respirometria baseia-se na utilização da medida da taxa de consumo de oxigênio (TCO) pela respiração de microrganismos durante o processo de degradação de substratos. Dessa forma, pode-se estimar o tempo de estabilização e avaliar a toxicidade de um efluente, uma vez que, cargas toxicas resultam em diminuição da velocidade de consumo de oxigênio (FERNANDES, 2001). A TCO no final do processo no RBSB foi de $17,64 \mathrm{mg} \cdot \mathrm{L}^{-1} \cdot \mathrm{h}^{-1}$ e no RBSE encontrou-se TCO de14,46 mg. $\mathrm{L}^{-1} \cdot \mathrm{h}^{-1}$.

Quando se compara os resultados não é possível identificar uma variação grande entre as TCO's, mas a diferença do consumo pode estar relacionada com a quantidade de microrganismos presente em cada RBS, onde o RBSB apresentou ao longo dos 42 dias de operação um valor de UFC/mL superior ao RBSE.

Em um reator com biomassa em suspensão operado com esgoto sanitário, Bueno (2011) encontrou valor de 10,0 mg. $\mathrm{L}^{-1} \cdot \mathrm{h}^{-1}$, já Costa, Ferreira e Van Haandel ( , (2007) em seu trabalho encontraram um valor de $14,3 \mathrm{mg} \cdot \mathrm{L}^{-1} \cdot \mathrm{h}^{-1}$ de TCO endógena. 

Ambiental

\section{CONCLUSÃO}

Os resultados indicam que a bucha vegetal apresenta-se mais favorável ao processo de formação de biofilme do que a espuma de poliuretano. Quanto aos organismos nitrificantes constatou-se que as condições ambientais em ambos os reatores (RBSB e RBSE) possivelmente vieram a interferir na ação e desenvolvimento destes organismos.

Da análise microscópica a fresco realizada nas lâminas contidas nos reatores foi possível observar que no RBSB havia uma frequência menor de organismos como rotíferos e protozoários, o que pode ter favorecido o processo de formação de biofilme na bucha vegetal.

\section{REFERÊNCIAS BIBLIOGRÁFICAS}

AGRA, C. de A.. Tratamento de águas residuárias domésticas em reatores de biomassa dispersa e biomassa aderida. 2009. 89f. Dissertação (Mestrado em Desenvolvimento e Meio Ambiente) - Universidade Federal da Paraíba, Campina Grande, 2009.

APHA, AWWA, WEF Standards Methods for the Examination of Water e Wastewater, $21^{\circ}$ ed. Washington. D.C, 2005.

BITTON, G. Wastewater Microbiology, New York: Wiley Liss Pub, 2005, 746p.

BUENO, R. de F. Nitrificação e desnitrificação simultânea em reator com biomassa em suspensão e fluxo contínuo de esgoto. 2011. 143f. Dissertação (Mestrado em Saúde Pública) Universidade de São Paulo, Faculdade de saúde pública, São Paulo, 2011.

BREITENBUCHER, K. et al. Open-pore sintered glass as a high-efficiency support media in bioreactors: new results and long-term experiences achieved in high-rate anaerobic digestion, Water Sci. Technol, v.22, p.25-32, 1990.

CHARACKLIS W. G.; MCFETERS G.A; MARSHALL K.C. Physiological ecology in biofilm systems. In: Characklis W.G, Marshall K.C. Biofilms. New York: John Wiley \& Sons, 1990. p. 94-341.

COHN, S.; HAYES, A.; RENAULT K. The Effect of Substrate Variation on Biofilm Growth for Use in Wastewater Treatment. 2010. 113f. Projeto (Bacharelado em Ciências) - Worcester Polytechnic Institute, Estados Unidos, 2010. Disponível em: < http://www.wpi.edu/Pubs/E-project/Available/Eproject-040810-131800/unrestricted/SCohnAHayesKRenaultMQP.pdf>. Acesso em: 18 Jan. 2015.

COMEAU, Y. Microbial metabolism. In: Henze, M. et al; Van Loosdrecht, M.; Ekama, G.; Brdjanovic, D. Biological wastewater treatment: Principles, modeling and design. IWA publishing, 2008, p. 932.

COSTA, A. G.; FERREIRA, A. F.; VAN HAANDEL, A. Monitoramento da atividade bacteriana de um sistema de lodos ativados bardenpho por meio da respirometria. Eng. sanit. ambient., v.12, n.1, p. 17-23, 2007. 
DUBOIS, M. et al. Calorimetric method for determination of sugars and related substances. Anal. Chem, v. 28, p.350- 356, 1956.

EGLI K. et al. Community analysis of ammonia and nitrite oxidizers during start-up nitration reactor. Applied and Environmental Microbiology, v. 69, n. 6, p. 3213-3222, 2003.

EIKELBOOM, D. H. Process Control of Activated Sludge Plants by Microscopic Investigation. Manual, Londres: IWA, 2000.

FERNANDES, J. G. S. et al. Utilização da respirometria no controle operacional de sistemas aeróbios de tratamento de águas residuárias - A experiência da Cetrel, Eng. Sanit. Ambient., v.6, n.4, 2001.

FIGUEIREDO, M. G.; DOMINGUES, V. B. Microbiologia de Lodos Ativados. CETESB Companhia de Tecnologia de Saneamento Ambiental. São Paulo: CETESB, 1997, 48 p.

GARCIA, M. L. et al. Effects of bed materials on the performance of an anaerobic sequencing batch biofilm reactor treating domestic sewage. Journal of Environmental Management, v. 88, p. 14711477, 2008.

HUYSMAN, P. et al. Factors affecting the colonization of non porous packing material in model upflow methane reactors. Biotechnology Letters, v.5, p.643-648, 1983.

KOKARE, C. R. et al. Biofilm: Importance and applications. Indian Journal of Biotechnology. v. 8, p. 159-168, 2009.

MELO, L. F. Biofilm formation and its role in fixed film processes. In: HORAN, N. J. (Org). Handbook of Water and Wastewater Microbiology, California: Elsever, 2003.

Tratamento Biológico de água e efluentes líquidos: Biomassa Fixa versus Biomassa em Suspensão. Universidade do Minho, Braga. 1996. Disponível em:< http://repositorium.sdum.uminho.pt/handle/1822/3994 >. Acesso em: 15 jan. 2015.

MENDONÇA, L.C. Microbiologia e cinética de sistemas de lodos ativados como pós-tratamento de efluente de reator anaeróbio de leito expandido. 2002. 184f. Tese (Doutorado em Engenharia Civil)- Universidade de São Paulo, São Carlos, 2002.

OGBONNA, J. C.; MASHIMA, H.; TANAKA, H. Scale up of fuel ethanol production from sugar beet juice using loofa sponge immobilized bioreactor. Bioresource Technology, v. 76, n. 1, p. 1-8, 2001.

O'REILLY, E., RODGERS, M. ZHAN, X. M. Pumped flow biofilm reactors (PFBR) for treating municipal wasterwater. Water Science \& Tecnology, v. 57, n. 12; p. 1857-1865, 2008.

PEKDEMIR. T. et al. Process intensification in wastewater treatment: ferrous iron removal by a sustainable membrane bioreactor system. J. Chem. Technol. Biotechnol, v. 78, n.7, p. 773-780, 2003.

SAEED A.; IQBAL M. Loofa (Luffa cylindrica) Sponge: Review of Development of the Biomatrix as a Tool for Biotechnological Applications. Biotechnol Prog, v. 29, n.3, p.573-600, 2013.

SCHNEIDER, E. E. Avaliação de um reator de leito móvel com biofilme para tratamento de efluente da indústria do petróleo, com posterior ozonização acoplada a carvão ativado granular com biofilme. 2010. 191f. Dissertação (Mestrado em Engenharia Química) - Universidade Federal do Rio de Janeiro, Rio de Janeiro, 2010.

VILLAVERDE, S. Recent developments on biological nutrient removal processes for wastewater treatment. Environmental Science and BioTechology. v. 3, p. 171-183, 2004. 
VAZOLLER, R. F. Biodiversidade: Oportunidade e Perspectivas Tecnológicas. Workshop. Campinas, São Paulo, Universidade de São Paulo, 1996, p.1-24.

WOLFF, D. B.; PAUL, E.; COSTA, R. H. R. de. Influência do tipo de material suporte no desempenho de reatores biológicos de leito móvel na remoção de carbono e nitrificação de esgoto sanitário. Eng Sanit Ambient, v.15, n.2, abr/jun 2010, p.149-154.

WOSIACK, P. A. et al. Removal of COD and nitrogen from animal food plant wastewater in an intermittently-aerated structured-bed reactor. Journal of Environmental Management, v. 154, p. 145-150, 2015.

YU-KUO LIU. et al. Characteristics of loofa (Luffa cylindrica) sponge as a carrier for plant cell immobilization. Journal of Fermentation and Bioengineering, v 85, p. 416-421, 1998. 